\title{
Factors affecting male-male competition in thirteen-lined ground squirrels
}

\author{
P.L. Schwagmeyer* and C.H. Brown ** \\ Psychobiology Area, University of Michigan, Ann Arbor, Michigan 48109, USA
}

Received August 2, 1982 / Accepted March 30, 1983

\begin{abstract}
Summary. Intrasexual conflict and mating behavior were observed in a population of thirteen-lined ground squirrels (Spermophilus tridecemlineatus). Success in male-male competition was related strongly to male weight, whereas both the weight and age of males were correlated positively with estimated mating success.

Between-season fluctuations in the density of reproductive males were analyzed in terms of their effects on the population's operational sex ratio (OSR). Changes in the OSR corresponded with changes in behavioral aspects of sexual selection: when the OSR became less male-biased, intrasexual conflict was reduced, sexual interference declined, and males essentially had unrestricted access to estrous females. Opportunities for female choice likewise became limited as estrous females rarely were approached by more than one male.
\end{abstract}

\section{Introduction}

Emlen and Oring (1977) argued for an image of mating systems as labile rather than species-specific: Because ecological factors that affect the ability to monopolize mates (or resources critical to mate acquisition) often vary across populations, the mating systems of those populations may differ. Similarly, certain changes over time within a population are expected to produce shifts in methods of acquiring mates or shifts in the degree of reproductive competition.

\footnotetext{
* Present address: Department of Psychology, University of Oklahoma, Norman, Oklahoma 73019, USA

** Present address: Department of Psychology, University of ${ }^{*}$ Missouri, Columbia, Missouri 65211, USA
}

The ecological features cited by Emlen and Oring as influencing access to multiple mates include the spatial distribution of resources and the spatial distribution and synchrony of sexual receptivity in members of the limiting sex. They suggested the operational sex ratio (OSR) as an empirical measure of how readily mates can be monopolized; the OSR, defined as "the average ratio of fertilizable females to sexually active males at any given time" (p. 216), combines the effects of mate availability and competitor density. Male-biased OSRs were predicted to be associated with polygyny and competition among males for mates; conversely, female-biased OSRs were predicted to be associated with polyandry and female-female competition. Emlen and Oring also hypothesized that the intensity of sexual selection and degree of intrasexual competition should be a function of OSR skew.

Thus according to their model, OSR variability can promote intraspecific diversity in mating systems and levels of reproductive competition. We report changes in the OSR that occurred in a population of thirteen-lined ground squirrels (Spermophilus tridecemlineatus) over successive breeding seasons. The mating system(s) of this species had not been described previously, although it had been noted that, in contrast to most species of ground-dwelling sciurids, copulations occurred aboveground (McCarley 1966). Preliminary observations of mating behavior in 1977 revealed conspicuous male-male conflict in the form of chases, occasional fights, and sexual interference. In 1978 we quantified (1) these high levels of intrasexual competition, as well as (2) multiple mating by females, and (3) the relationships among male age, weight, success in conflict, and mating success. During the subsequent year the density of sexually active males, and the degree of male-bias in the 
OSR, dropped substantially. We describe corresponding changes in intrasexual competition and multiple mating by females.

\section{Material and methods}

The study site was a 5.6 ha portion of the University of Michigan's Matthaei Botanical Gardens that was surrounded on most sides by unmowed areas, pond, marsh, or woodland. With the exception of a 0.6 ha tract, it was regularly mowed to a height of $50 \mathrm{~mm}$ and contained a variety of ornamental trees and shrubs. The site is described in further detail in Schwagmeyer (1979).

Ground squirrels resident in the study area were toeclipped for permanent identification and marked distinctively with hair-dye to permit identification at a distance. During 1977-79, males began emerging from hibernation in the latter half of March, and females began appearing aboveground approximately three weeks later. Preliminary observations of the population's mating activity were conducted in 1977, however, most of the data presented below is based on over $500 \mathrm{~h}$ of field work during the pre-mating and mating periods of 1978 and 1979 (approximately $270 \mathrm{~h}$ per season; typically two observers present). Prior to the emergence of females, male behavior was observed via focal animal sampling, with the nature (chase, with or without contact), location, outcome, and identity of participants recorded for each interaction. Following the onset of breeding, our behavioral sampling technique was modified to maximize the number of sexual interactions observed. We surveyed the study area throughout each day to monitor the receptivity of females; those females that appeared to be nearing estrus (i.e., subject to repeated and persistent investigation by males) or were in estrus became focal animals. Because copulations occurred aboveground, we were able to base estimates of male mating success on observational sampling of sexual activity. We attempted to maintain constant surveillance over females during the entire period of sexual receptivity; however, observations were at times interrupted by the squirrels' movement into tall vegetation. On those occasions and when visual contact with a female was broken by her entry into a burrow, the observer remained in the area and resumed data collection upon her reappearance. The mean duration of observation per estrous female was $4.8 \mathrm{~h}(\mathrm{SD}=1.9)$ in 1978 and $4.1 \mathrm{~h}(\mathrm{SD}=1.9)$ in 1979. The identities of males interacting with or in the vicinity of estrous females were recorded, and data pertaining to their interactions with one another noted. In addition, male approaches to females, mount durations, and female responses (including the distance, direction, and vigor of movements) were recorded. We routinely monitored females from diverse areas of the study site in order to avoid biasing the data in favor of males that frequented particular locations.

In all 3 years of the study, females trapped for dye-marking were examined for signs of genital swelling and opening of the vagina. In order to determine the correspondence between sexual behavior and estrous status, females of known sexual history were captured for inspection in 1978 and 1979. To minimize disruption of sexually active females, trapping was attempted only when males were absent. All individuals were weighed to the nearest $0.5 \mathrm{~g}$ as a routine step in the dye-marking procedure. Because trapping of males interfered with behavioral observations of their mating success and competitive ability, they were re-weighed during the breeding season only if they could be captured opportunistically. The male weight data presented here consequently are biased toward weight at emergence from hibernation. Age data are based on records of juvenile captures dating from 1976 through 1978.

\section{Results}

Breeding activity in the study population occurred over an 11 day period in 1977, 12 days in 1978. In 1979 , the first female to emerge from hibernation was sexually active on April 17 th, but then copulated again a week later. Because her first mating was apparently ineffective, and because no other sexual activity was observed until April 25th, the breeding season for that year was considered to have begun on the 24th, and to have lasted for 14 days. For all 3 years, breeding season dates were confirmed roughly by comparison with timing of subsequent juvenile emergence from natal burrows.

In 1977 and 1978, yearlings of both sexes were reproductively active, and yearling males formed substantial percentages of the total numbers of reproductive males (1977: 70\%; 1978: 50\%). By contrast, 1979 male yearlings were not sexually active. They emerged later from hibernation: an average of two days after the first day of the mating season, whereas yearling males in 1978 had appeared aboveground an average of 13.5 days before the onset of breeding. Also, 1979 yearling males did not interact aggressively with other males or pursue females. They weighed significantly less than the 1979 two-year-old males (Table 1), and examination revealed that the testes of two (of four) had not descended.

Operational sex ratios were estimated in order to examine the relative influences of season duration and male and female densities on the potential for intrasexual competition. We saw no evidence for strong synchrony of estrus within breeding seasons; in 1978, for example, the number of females known to have been in estrus on any day ranged from zero to three. (The emergence of litters from natal burrows was distributed similarly, without sharp peaks in the number of litters emerging each day.) The estimated OSRs consequently were cal-

Table 1. Male age and weight by season; $\bar{x}=$ weight in grams based on 1.4 weighings per male in $1978,2.2$ weighings per reproductive male in 1979, and weight upon emergence for 1979 yearlings

\begin{tabular}{|c|c|c|c|c|c|c|}
\hline \multirow[t]{2}{*}{ Age-class } & \multicolumn{3}{|c|}{1978} & \multicolumn{3}{|c|}{1979} \\
\hline & $n$ & $\bar{x}$ & Range & $n$ & $\bar{x}$ & Range \\
\hline$\geqq 3$ years & 2 & $134^{\mathrm{a}}$ & $125-144$ & 0 & - & - \\
\hline 2 years & 2 & $110^{\mathrm{a}}$ & $103-118$ & 4 & $132^{\mathrm{b}}$ & $110-143$ \\
\hline 1 year & 4 & $114^{\mathrm{a}}$ & $97-128$ & 4 & $86^{b}$ & $77-94$ \\
\hline
\end{tabular}

a Kruskal-Wallis $H=2.43, P>0.10$

b Mann-Whitney $U=0, P=0.014$, one-tailed 
Table 2. Population and operational sex ratios by year, $q: \varnothing$

\begin{tabular}{llll}
\hline & 1977 & 1978 & 1979 \\
\hline $\begin{array}{l}\text { Adult population } \\
\text { sex ratio }\end{array}$ & $19: 10$ & $24: 8$ & $30: 4$ \\
$\begin{array}{l}\text { Duration of breeding } \\
\text { season (days) }\end{array}$ & 11 & 12 & 14 \\
$\begin{array}{l}\text { Estimated operational } \\
\text { sex ratio }\end{array}$ & $1.7: 10$ & $2: 8$ & $2.14: 4$ \\
$\begin{array}{l}\text { Observed operational } \\
\text { sex ratio }\end{array}$ & & $1: 2.5$ & $1: 1.5$ \\
\hline
\end{tabular}

culated with the assumption of minimum female synchrony and on a per-day basis, i.e., the total number of females in the population was divided by the number of days in that breeding season. These estimates (Table 2) indicate that several males should have been available per estrous female in 1977 and 1978; in 1979, by contrast, the decline in density of sexually active males produced a marked reduction in the number of males per sexually receptive female.

\section{Sexual behavior}

Early laboratory work on reproductive cycling in this species indicated that onset of estrus is accompanied by opening of the vagina and enlargement and reddening of the external genitalia (Foster 1934). Of 10 females examined within $5-6 \mathrm{~h}$ after copulating, all fit that description. Vaginal opening and enlargement occurred rapidly: Of 11 females inspected from $2.5-72 \mathrm{~h}$ before mating, none had a perforate vagina, although genital swelling was noted in four of seven examined within $48 \mathrm{~h}$ of mating onset. The average duration of estrus could not be specified accurately: Some females were sexually active (defined by the interval between their first and last observed copulations) for as long as $6 \mathrm{~h}$; the mating activity of others lasted for less than $1 \mathrm{~h}$ and appeared to be restricted simply by the duration of male attendance.

The most reliable behavioral indicators of the onset of estrus were persistence of male attention and the occurrence of prolonged mounts. Males approached and investigated both estrous and non-estrous females, and non-estrous females occasionally were subject to male mounting attempts. However, male visits with non-estrous females during the breeding season were brief, usually lasting for less than $10 \mathrm{~min}$ (median $=8 \mathrm{~min}$ for 27 timed approaches), whereas males followed, repeatedly approached, and/or waited outside of the burrows of estrous females for a median duration of $74 \mathrm{~min}$ $(n=35)$. Female responses to male approaches did not change conspicuously with the onset of estrus: They continued to evade males, and rarely followed or approached them.

Intromission and ejaculation could not be detected in the field, and mounts varied in duration from very brief contact $(<10 \mathrm{~s})$ to $17 \mathrm{~min}$. In order to exclude copulatory attempts that did not appear to involve genital contact, the estimates of male mating success given below are based on operationally defining copulation as a mount that lasted for at least $1 \mathrm{~min}$. This criterion served primarily as a baseline in determining opportunity for insemination: The average copulation duration was $4.7 \mathrm{~min}(n=51)$, and males frequently copulated repeatedly with the same female.

\section{Intrasexual competition}

Relative to both female movements and to their home range areas during the remainder of the year, reproductive males traveled extensively during the mating season. Although we did not sample male movements formally, the data collected on location of sexual encounters indicate that some males covered well over 1 ha in their searches for females. An exception to this general pattern occurred in 1979 , when one individual confined his activity to an area approximately 0.5 ha in size, and his attention to the 12 females residing there.

A total of 141 interactions between males of known identity was observed during the pre-mating and mating periods of 1978 , whereas only 33 were observed during the same time periods of 1979. Gross comparison of the average number of conflicts observed per male per season suggests that males participated in fewer intrasexual interactions in 1979 than in 1978 (1978: $\bar{x}$ conflicts/ male $=35.1, \mathrm{SD}=20.2 ; 1979: \bar{x}=16.5, \mathrm{SD}=11.6$, Mann-Whitney $U=6, P=0.055$, one-tailed). Analysis of the incidence of conflicts over estrous females provides further evidence that male-male interaction declined significantly in 1979: An average of 1.25 conflicts precipitated by the approach of one male to a female being courted by a competitor occurred per hour of estrus in 1978; in 1979 the average rate fell to 0.38 conflicts per hour of estrus (Mann-Whitney $U=20.5 ; P<0.025$, one-tailed). Mounts or copulations were disrupted by male competitors significantly more frequently in 1978 ( $\bar{x}$ rate $=0.28$ disruptions/estrus hour) than in 1979 $(\bar{x}=0.0$ disruptions/estrus hour; Mann-Whitney $U=24 ; P<0.05$, one-tailed).

The majority of interactions between males consisted simply of chases; physical contact (biting 


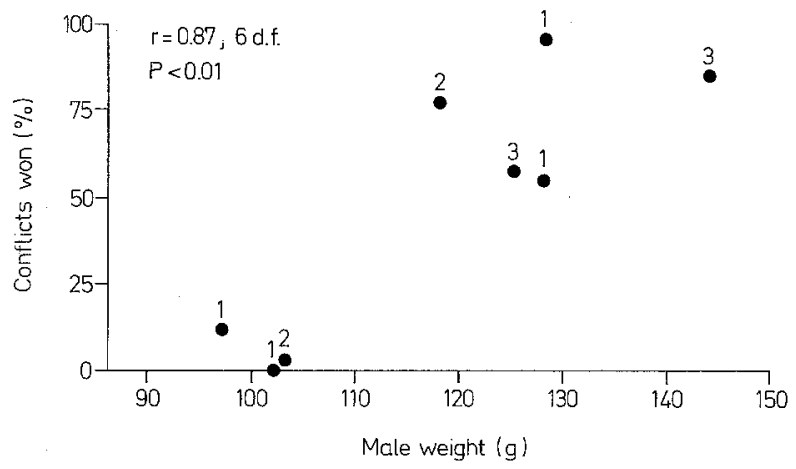

Fig. 1. Male weight and success in intrasexual conflict, 1978. Male age is indicated above each data point

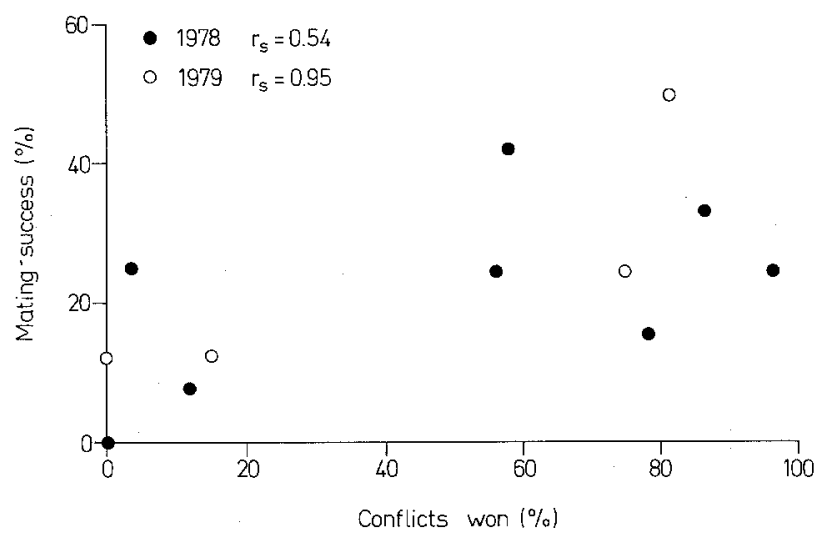

Fig. 2. Success in intrasexual conflict and mating success. Mating success estimates were derived from calculation of the percentage of sampled females with which each male copulated. $0=1979$ data $;=1978$ data

or fighting) was observed during only eight (5.7\%) of the 1978 and four $(12.1 \%)$ of the 1979 interactions. In both years, individuals interacted at least once with most of the other sexually active males in the population $(\bar{x}=5$ different opponents per male in $1978 ; \bar{x}=3$ different opponents per male in 1979), and in both years, the outcome of conflicts between particular males appeared to be independent of the interaction site. Reversal of the most frequent result of conflicts (i.e., dominance) within a given dyad was rare (5 of 141 conflicts in 1978,0 of 33 conflicts in 1979).

Intrasexual competitive ability was measured by calculating the percentage of conflicts won by each male, with chasing of a competitor from the encounter site considered a victory. On three occasions males withdrew simultaneously from the encounter site; those interactions were included in the participants' total number of conflicts, but not scored as victories. Because the 1978 data on malemale interactions represent the activities of three age classes and a greater number of individuals, they were chosen for analysis of the effects of age and weight on success in competition. The three age classes present in the population that year did not differ significantly in weight (Table 1). Regression analyses revealed that weight alone accounted for $76 \%$ of the variance in competitive ability (Fig. 1), while age alone accounted for only $10 \%$ $(r=0.32, d . f .=6, P>0.10)$. Combining the two factors did little to improve the precision of the relationship between weight and success in male-male competition $(R=0.87)$.

\section{Male mating success}

Twenty-four females resided on the study area during the 1978 breeding season; male mating success for that year was sampled during observation of $12(50 \%)$ of them. In 1979 the sexual behavior of eight of the 30 resident females $(27 \%)$ was monitored. Portions of an additional three females' mating activities were observed during the 2 years, but those data were excluded from analyses because of inadequate monitoring of their behavior (one estrous female remained in a burrow with a male for approximately $2 \mathrm{~h}$ during a rainstorm; the second persistently entered areas where vegetation hampered observation, and the third was discovered in copula in an area that we had failed to patrol regularly that day). In three cases where females exhibited two estrous periods, data collected during the first, apparently unsuccessful, estrus were eliminated from analyses.

The average number of mates per female and the average number of males approaching estrous females differed between the two seasons. Observed OSRs were calculated to gauge the actual number of males available to estrous females (Table 2). Averages for 1978 and 1979 were based on the number of males approaching estrous females, with approach defined so as to include both males that achieved contact with the female and males that interrupted the courtship of competitors, yet did not themselves gain access to the female. In 1978 estrous females were approached by an average of 2.5 males (range $=1-5$ ), whereas 1979 females were approached by an average of 1.5 males (Mann-Whitney $U=24.5 ; \quad P<0.05$, one-tailed). The number of mates per female showed a parallel decline in 1979: while six of the 1978 females $(50 \%)$ mated with more than one male $(\bar{x}$ mates per female $=1.75$, range $=1-3$ ), all estrous females observed in 1979 had a single sexual partner. 
Multiple regression of male age and weight on 1978 mating success revealed that those variables accounted separately for about equal amounts of the variance in mating success (age: $r=0.73 ; d . f$. $=$ $6, P<0.05$; weight: $r=0.72 ; d . f .=6, P<0.05$ ); together, they accounted for $70 \%$ of the variability in mating success $(r=0.84)$. With weight effects partialed out, the correlation between age and mating success was 0.62 ; with age effects removed, the correlation between mating success and weight was 0.59 .

Success in male-male conflict was not significantly related to male mating success in either 1978 $\left(r_{s}=0.54 ; d . f .=6, P>0.05\right)$ or $1979 \quad\left(r_{s}=0.95\right.$; $d . f .=2, P>0.05$ ), although in both years the two variables tended to be positively associated (Fig. 2).

\section{Discussion}

Male thirteen-lined ground squirrels actively searched for estrous females in a scramble competition (Wells 1977; Alcock 1980) fashion. They did not display site-specific dominance; with one exception, they did not restrict their activities to a defendable area or their attention to particular females.

Age and size have been documented as correlates of male mating success in a variety of polygynous organisms (e.g., Clutton-Brock et al. 1979; Berven 1981; McCauley 1982). The results from 1978 similarly indicate age and larger body size to be reproductively advantageous to male $S$. tridecemlineatus when they are faced with relatively intense competition. Because weight and success in male-male conflict were strongly associated, the mating advantage of large males could be derived from their social domination of competitors. The mating advantage of older males cannot be traced through the male-male conflict mechanism, however, because there was no significant effect of age on success in confrontations. The superiority of older males could be based on very subtly expressed female preferences (Schwagmeyer, in press); alternatively, older males simply could be more proficient at locating estrous females.

The failure of yearling males to breed in 1979 and the consequent decline in density of sexually active males permitted post hoc analysis of the effects of OSR on sexual selection processes. In particular, they allowed verification of Emlen and Oring's prediction that intrasexual competition should be most extreme under conditions of strongly skewed OSR. Both the estimated and ob- served OSRs within the study population were less male-biased in 1979 than during preceding years, and there were two major types of changes occurring in that season: (1) In support of Emlen and Oring's prediction, the total number of intrasexual conflicts fell dramatically, the number of conflicts over estrous females declined significantly, and sexual interference in the form of disruption of mounts or copulations was reduced. (2) In contrast to the 1978 results and to those from populations of S. tridecemlineatus in Texas (McCarley 1966) and Oklahoma (personal observation), females were not observed to mate multiply in 1979, and few were even approached by more than one male while in estrus: The opportunities for female choice to affect male mating success were curtailed as the male-bias in OSR was reduced.

Our data thus support Emlen and Oring's (1977) predicted relationship between OSR and the intensity of intrasexual competition. The results also suggest that shifts in the OSR may have a strong impact on opportunities for female choice, perhaps particularly when sexual encounters are contingent on males' locating dispersed receptive females. Though Emlen and Oring further specified that the intensity of sexual selection (i.e., variance in male reproductive or mating success) should be diminished by a reduction in OSR skew, we are unable to evaluate that hypothesis because our between-season comparison was confounded by changes in multiple mating and the age-size variability of males. Recent work indicates that variance in male mating success within a season could be influenced by those factors, as well as by OSR: Howard (1981) found yearly changes in the age-size distribution of male bullfrogs (Rana catesbeiana) to be accompanied by changes in variability of male mating success; in this population of $S$. tridecemlineatus multiple mating by females appears to affect variance in male mating success (Schwagmeyer, in press). Thus, seasonal differences in the intensity of sexual selection on males, as measured by variance in mating success, could be due to (1) changes in variability among males in phenotypic correlates of mating success; or (2) changes in the OSR. In some systems, (3) changes in resource availability (see Borgia 1979; Thornhill 1981) and/or (4) changes in the incidence of multiple mating by females may also influence variance in mating success. Experimental manipulations may be required for isolation of the effect of any one of these.

Acknowledgments. We thank the staff of the Botanical Gardens for their cooperation, D. Mock for his comments on the manu- 
script, C. Prosen and D. Silverman for field assistance, and B. Ross for running the regression analyses. Financial support was provided by an NIMH Predoctoral Fellowship to P.L.S.

\section{References}

Alcock J (1980) Natural selection and the mating systems of solitary bees. Am Sci 68:146-153

Berven K (1981) Mate choice in the wood frog, Rana sylvaticus. Evolution 35:707-722

Borgia G (1979) Sexual selection and the evolution of mating systems. In: Blum M, Blum N (eds) Sexual selection and reproductive competition in insects. Academic Press, New York, pp 19-80

Clutton-Brock T, Albon S, Gibson R, Guinness F (1979) The logical stag: Adaptive aspects of fighting in red deer (Cervus elaphus L.). Anim Behav 27:211-225

Emlen S, Oring L (1977) Ecology, sexual selection and the evolution of mating systems. Science 198:215-233

Foster M (1934) The reproductive cycle in the female ground squirrel, Citellus tridecemlineatus (Mitchell). Am J Anat $54: 487-511$
Howard R (1981) Male age-size distribution and male mating success in bullfrogs. In: Alexander R, Tinkle D (eds) Natural selection and social behavior. Chiron Press, New York, pp 61-77

McCarley H (1966) Annual cycle, population dynamics and adaptive behavior of Citellus tridecemineatus. J Mammal 47:294-316

McCauley D (1982) The behavioural components of sexual selection in the milkweed beetle Tetraopes tetraophthalmus. Anim Behav 30:23-28

Schwagmeyer P (1979) The function of alarm calling behavior in Spermophilus tridecemlineatus, the thirteen-lined ground squirrel. PhD thesis, University of Michigan, Ann Arbor

Schwagmeyer P (in press) Multiple mating and intersexual selection in the thirteen-lined ground squirrel. In: Michener G, Murie J (eds) Biology of ground-dwelling squirrels: Annual cycles, behavioral ecology, and sociality. University of Nebraska Press, Lincoln

Thornhill R (1981) Panorpa (Mecoptera: Panorpidae) scorpionflies: Systems for understanding resource-defense polygyny and alternative male reproductive efforts. Annu Rev Ecol Syst 12:355-386

Wells K (1977) The social behaviour of anuran amphibians. Anim Behav 25:666-693 